\title{
Dae Hong Min, M.D., Ph.D., 1934 to 2015
}

\author{
Tae Hui Bae, Woo Seob Kim, Han Koo Kim
}

Department of Plastic and Reconstructive Surgery, Chung-Ang University Hospital, Chung-Ang University

College of Medicine, Seoul, Korea

Dae Hong Min, M.D., Ph.D., a past president of the Korean Society of Plastic and Reconstructive Surgeons and a past president of the Korean Society for Aesthetic Plastic Surgery, died in Seoul on June 1, 2015. He was 81 years old.

Dr. Min was born in Seoul on March 3, 1934. He graduated with a degree in medicine from Yonsei University in 1958. From 1958 to 1962, he served in the Navy of the Republic of Korea as a senior lieutenant. He then trained in general surgery and plastic surgery at Yonsei University Severance Hospital from 1962 to 1967 . He was the first trainee in plastic surgery under Dr. Jae Duck Yu, who was the first practitioner of plastic and reconstructive surgery in Korea.

Dr. Min remained on the staff at Yonsei University Severance Hospital until 1971.

On May 15, 1966, the Korean Society of Plastic Reconstructive Surgeons was established. Dr. Min was among the initial members of the organization and played a leadership role as executive director.

In 1972 he founded the Department of Plastic and Reconstructive Surgery at ChungAng University Hospital. He worked hard to train the upcoming generations until his retirement in 1999.

As one of the pioneers of Korean plastic and aesthetic surgery, Dr. Min served as the president of the Korean Society of Plastic and Reconstructive Surgeons (1980-1982), the president of the Korean Society for Aesthetic Plastic Surgery (1985-1990), and the chair of the Korean Society of Plastic and Reconstructive Surgeons (1990-1991).

His friends, colleagues, and students remember him as a true gentleman, teacher, and life mentor who lived as a leader in Korean Plastic Surgery (Figure).

\section{Correspondence: Woo Seob Kim}

Department of Plastic and Reconstructive Surgery, Chung-Ang University Hospital, Chung-Ang University College of

Medicine, 102 Heukseok-ro, Dongjak-gu, Seoul 06973, Korea

Tel: +82-2-6299-1615, Fax: +82-2-825-9880, E-mail: kimws@cau.ac.kr

No potential conflict of interest relevant to this article was reported.

Received: 20 Jun $2016 \bullet$ Revised: 2 Nov $2016 \bullet 8$ Nov 2016

pISSN: $2234-6163 \bullet$ elSSN: 2234-6171

https://doi.org/10.5999/aps.2016.43.6.624• Arch Plast Surg 2016;43:624 